\title{
EDITORIAL
}

\section{The Continued Value of the Surface ECG for the Diagnosis and Manage- ment of Conduction Disorders in the Era of Advanced Imaging Techniques}

\author{
Bryce Alexander ${ }^{1}$, Antoni Bayes de Luna ${ }^{2}$ and Adrian Baranchuk ${ }^{1}$
}

\author{
${ }^{I}$ Division of Cardiology, Queen's University, Kingston, Ontario, Canada $;{ }^{2}$ Autonomous University of Barcelona, Institut \\ Català Ciències Cardiovasculars-St. Paul Hospital, and Quiron Barcelona Hospital, Spain
}

In 2020 the surface electrocardiogram (ECG) remains one of the most frequently used diagnostic tests in cardiology, surpassed only by the stethoscope. ECGs are a frequently used diagnostic test during an initial patient presentation and can rapidly shift the clinical pathway followed. ECGs are used in the diagnosis and management of a diverse set of acute and chronic diseases and are useful for establishing management and prognosis. Accurate interpretation of ECG tracings is a core competency in many disciplines within medicine and is essential knowledge for the internist, the emergency medicine practitioner and the family doctor, to name only a few who interact with ECGs daily. In the setting of a known or suspected conduction disorder, the ECG is essential to rapidly establish the diagnosis and initiating treatment, which in many cases can be life-saving. When we were approached by Bentham Publishers to coordinate a special issue on the value of the surface ECG in conduction disorders, we were thrilled to accept the challenge.

The first challenge was to identify topics within this frame that are of interest, or that create enough controversy or that have evolved significantly during the last decade; to be part of a special volume. In this sense, we are happy to have collected topics that deserved an update or a deeper view from an expert eye.

The second task was to compare our list and create a list of world-wide experts that could approach the topic under their personal view. At the end of this process, we had a list of 9 topics and 9 groups of individuals from different parts of the world ready to take on this challenge. These authors worked extremely hard to develop the manuscripts that are contained within this issue.

The first paper is on Lyme carditis, led by Cynthia Yeung, an early-career researcher from Canada [1]. Lyme carditis is a new and rapidly evolving area of research and is an area that may be unfamiliar to many physicians [2]. The second paper, "The Wenckebach Phenomenon", belongs to Professor Martin Green and colleagues [3]. Professor Green has a special interest in the Wenckebach Phenomenon and his expert knowledge of the subject is clearly demonstrated in this review $[4,5]$. The third paper, on the epsilon wave, belongs to Dr. Pyotr Platonov, current Annual Chair of the International Society for Computerized Electrocardiology (ISCE), and Dr. Anneli Svensson from Sweden [6]. In this paper, the epsilon wave as an extreme form of depolarization delay is a presented and the history, mechanisms and implications of the epsilon wave is reviewed. The next paper, reviewing Right Bundle Branch Blocks was taken on by Professor Takanori Ikeda from Japan [7]. The third paper, reviewing the Fascicular Blocks is authored by Dr. Marcelo Elizari from Argentina, a direct disciple of Mauricio Rosenbaum, who was a leading figure in the original identification and publication of the hemiblocks [8, 9]. Dr. Elizari, current president of the Argentine Academy of Medicine and former President of the Argentine Cardiology Society (SAC), reviews the process behind their discovery and the pathophysiology of hemiblocks in this excellent paper. The next section, on conduction disease in the setting of an acute ST-elevation myocardial infarction is lead by Dr. Kjell Nikus from Finland [10, 11]. Dr. Nikus is considered a leader in the interpretation of the ECG in ischemic conditions. In this paper Dr. Nikus reviews the various conduction abnormalities that occur in the setting on an acute ST-elevation myocardial infarction. The next paper, on vectorcardiography and the main dromotropic disturbances was completed by Dr. Andres Perez-Riera from Brazil and colleagues [12]. He has a special interest in vectorcardiography and its uses which is apparent in this paper. The next section, on asymptomatic bradycardia, is lead by Dr. Goksel Çinier from Turkey on behalf of the International Society of Electrocardiology Young Community (ISE-YC) [13]. The ISE-YC is an initiative established in 2019 that is dedicated to building a global network for young trainees, physicians, and other healthcare professionals who are interested in the field of electrocardiology [14]. This excellent paper reviews the current evidence on the pathophysiology, diagnosis, evaluation and management of patients with asymptomatic bradyarrhythmias. The final section is written by our group at Queen's University in Kingston, Ontario, Canada and reviews atrial conduction abnormalities [15]. A recently published ECG risk score using only electrocardiographic P-wave analysis for the prediction of patients at risk for atrial fibrillation is presented [16].

We greatly enjoyed working on this special edition of Current Cardiology Reviews. It was a major editorial effort which involved several members of Bentham Science as well as our collaborators. Our special thanks go to the Editor-in-Chief of Current Cardiology Reviews, Dr. Antonio Crisafulli, who took the time to personally review every paper in this edition as well as the staff of Bentham Science. 
Medicine continues to rapidly evolve, and the field of cardiology is notable for having one of the highest rates of innovation and scientific progress in the area of diagnosis and imaging. Despite this, the 12-lead surface ECG remains an invaluable tool in the diagnosis and management of conduction disorders, even in the era of advanced imaging techniques.

We would like to dedicate this volume to all of our colleagues as well as up and coming trainees in the field of cardiovascular medicine.

\section{REFERENCES}

[1] Yeung C, Al-Turki M, Baranchuk A. The value of the surface ECG for the diagnosis and management of Lyme Carditis. Curr Cardiol Rev 2021; 17(1): 5-9.

http://dx.doi.org/10.2174/1573403X16666200312101751 PMID: 32164515

[2] Yeung C, Baranchuk A. Diagnosis and treatment of Lyme Carditis. J Am Coll Cardiol 2019; 73: 717-726. http://dx.doi.org/10.1016/j.jacc.2018.11.035 PMID: 30765038

[3] Hansom SP, Golian M, Green MS. The Wenckebach Phenomenon. Curr Cardiol Rev. 2021; 17(1): 10-16. http://dx.doi.org/10.2174/1573403X16666200719022142 PMID: 32682381

[4] Green MS, Guerra PG, Krahn AD. 2010 Canadian Cardiovascular Society/Canadian heart rhythm society training standards and maintenance of competency in adult clinical cardiac electrophysiology. Can J Cardiol 2011; 27: 859-861. http://dx.doi.org/10.1016/j.cjca.2011.03.002 PMID: 21723692

[5] Leather RA, Gardner M, Green MS, et al. Charting a course for cardiac electrophysiology training in Canada: The vital role of fellows in advanced cardiovascular care. Can J Cardiol 2013; 29: 1527-1530.

http://dx.doi.org/10.1016/j.cjca.2013.08.019 PMID: 24182759

[6] Platonov PG, Svensson A. Epsilon waves as an extreme form of depolarization delay: Focus on the arrhythmogenic right ventricular cardiomyopathy/dysplasia. Curr Cardiol Rev 2021: 17(1): 17-23.

http://dx.doi.org/10.2174/1573403X16666200810105029 PMID: 32778035

[7] Takanori Ikeda. Right bundle branch block: Current considerations. Curr Cardiol Rev 2021; 17(1): 24-30. http://dx.doi.org/10.2174/1573403X16666200708111553 PMID: 32640959

[8] Elizari MV, Acunzo RS, Ferreiro M. Hemiblocks Revisited. Circulation 2007; 115: 1154-1163. http://dx.doi.org/110.1161/CIRCULATIONAHA.106.637389

[9] Elizari M V. Fascicular Blocks: Update 2019. Curr Cardiol Rev. 2021: 17(1): 31-40. http://dx.doi.org/10.2174/1573403X16666200708111928 PMID: 32640960

[10] Nikus K, Birnbaum Y, Fiol-Sala M, Rankinen J, Luna AB de. Conduction disorders in the setting of acute STEMI. Curr Cardiol Rev. 2021: 17(1); 4149.

http://dx.doi.org/10.2174/1573403X16666200702121937 PMID: 32614749

[11] Nikus K, Birnbaum Y, Eskola M, Sclarovsky S, Zhong-qun Z, Pahlm O. Updated electrocardiographic classification of acute coronary syndromes. Curr Cardiol Rev 2014; 10: 229-236. http://dx.doi.org/10.2174/1573403x10666140514102754 PMID: 24827799

[12] Pérez-Riera AR, Barbosa-Barros R, Daminello-Raimundo R, de Abreu LC, Nikus K. The vectorcardiogram and the main dromotropic disturbances. Curr Cardiol Rev. 2021; 17(1): 50-59. http://dx.doi.org/10.2174/1573403X16666200810105504 PMID: 32778036

[13] Çinier G, Haseeb S, Bazoukis G, Yeung C, Gül EE. Evaluation and management of asymptomatic bradyarrhythmias. Curr Cardiol Rev 2021; 17(1): 60-67.

http://dx.doi.org/10.2174/1573403X16666200721154143 PMID: 32693770

[14] Çinier G, Haseeb S, Yeung C, et al. International society of electrocardiology young community. J Electrocardiol 2019; 54: 69-71. http://dx.doi.org/10.1016/j.jelectrocard.2019.03.001 PMID: 30928819

[15] Alexander B, Tse G, Martinez-Selles M, Baranchuk A. Atrial Conduction Disorders. Curr Cardiol Rev. 2021; 17(1): 68-73. http://dx.doi.org/10.2174/1573403X17666210112161524

[16] Alexander B, Milden J, Hazim B, et al. New electrocardiographic score for the prediction of atrial fibrillation: The MVP ECG risk score (morphologyvoltage-P-wave duration). Ann Noninvasive Electrocardiol. 2019; 24: 1-7.

http://dx.doi.org/10.1111/anec.12669 PMID: 31184409

Adrian Baranchuk

(Guest Editor)

Professor of Medicine

Cardiac Electrophysiology and Pacing

76 Stuart St

Kingston General Hospital K7L 2V7

Queen's University

Tel: 6135496666 ext 3801

Fax: 6135481387

E-mail: barancha@kgh.kari.net 